\title{
Tension Pneumothorax after Attempting Insertion of a Central Venous Catheter
}

\author{
Ki Hoon Kim \\ Department of Surgery, Inje University Haeundae Paik Hospital, Inje University College of Medicine, Busan, Korea
}

\begin{abstract}
A 17-year-old female patient was admitted to the emergency department of our hospital with dyspnea, which had presented 1 day earlier but had worsened despite treatment at another hospital. Before the onset of dyspnea, she had been undergoing follow-up in our pediatrics department because of repetitive aspiration pneumonia associated with cerebral palsy. On admission, her vital signs revealed a blood pressure of $60 / 40 \mathrm{mmHg}$, a temperature of $38^{\circ} \mathrm{C}$, and a heart rate of $185 \mathrm{bpm}$. Arterial blood gas analysis showed pH 7.09, $\mathrm{pCO}_{2} 67 \mathrm{mmHg}, \mathrm{pO}_{2}$ $53 \mathrm{mmHg}$, and $\mathrm{O}_{2}$ saturation $72 \%$. Central venous catheterization was attempted under mechanical ventilation into the right subclavian vein without success. While undergoing another catheterization into the left subclavian vein, the patient went into cardiac arrest and required cardiopulmonary resuscitation (CPR). Spontaneous circulation returned 5 minutes after CPR, but a right-sided tension pneumothorax was detected on chest radiography (Figure 1). After a thoracostomy was performed, her tension pneumothorax improved immediately (Figure 2). The patient was transferred to an intensive care unit because of sepsis resulting from aspiration pneumonia. The chest tube was removed 4 days after placement, and the patient was discharged 40 days after admission.

Pneumothorax is the one of the most frequent complications during central venous catheterization, especially after subclavian vein catheterization [1,2]. Tension pneumothorax occurs due to progressive accumulation of intrapleural air in the thoracic cavity caused by a valve effect during respiration. Positive pressure ventilation may exacerbate a tension pneumothorax [3,4]. Progressive increased intrathoracic pressure in the pleural space pushes the mediastinum to the opposite hemithorax and obstructs venous return to the heart. This leads to circulatory instability and may result in cardiorespiratory arrest. To prevent life-threatening situations caused by tension pneumothorax, it is important to detect these occurrences early and decompress them quickly.
\end{abstract}

\section{CONFLICT OF INTEREST}

No potential conflict of interest relevant to this article was reported.

\section{ORCID}

Ki Hoon Kim

https://orcid.org/0000-0003-2008-7572

\section{Image in Critical Care}

Received: December 13, 2017

Revised: April 21, 2018

Accepted: August 17, 2018

Corresponding author

Ki Hoon Kim

Department of Surgery, Inje University Haeundae Paik Hospital, 875 Haeun-daero, Haeundae-gu, Busan 48108, Korea

Tel: $+82-51-797-0260$

Fax: +82-51-797-0276

E-mail: medhun@hanmail.net

Copyright () 2018 The Korean Society of Critical Care Medicine

This is an Open Access article distributed under the terms of Creative Attributions Non-Commercial License (http:// creativecommons.org/li-censes/by-nc/4.0/) which permits unrestricted noncommercial use, distribution, and reproduction in any medium, provided the original work is properly cited. 


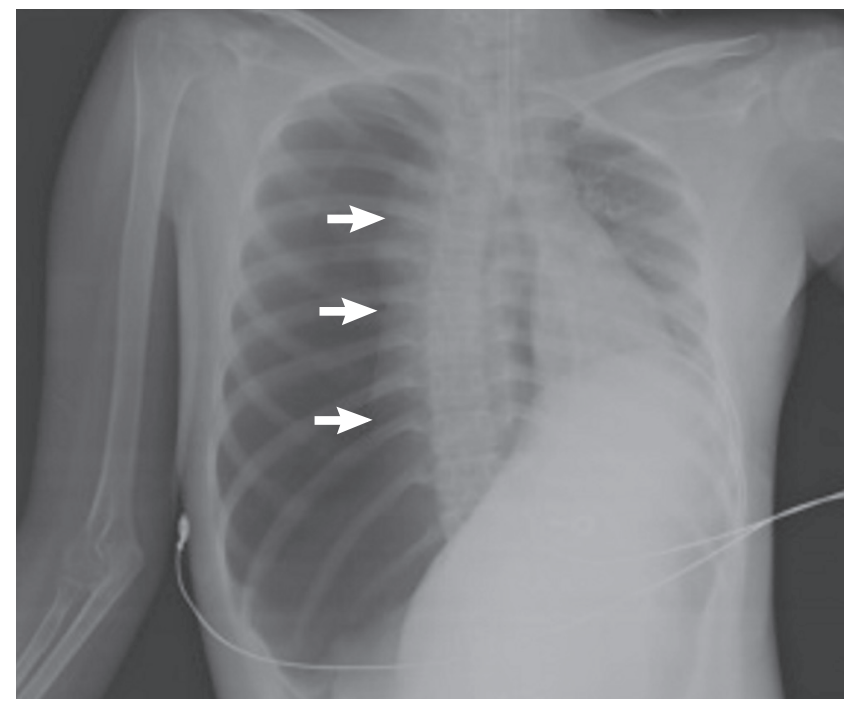

Figure 1. Chest X-ray showing right tension pneumothorax with mediastinal shifting to the left side. The right lung is completely collapsed (arrows), and the trachea is pushed to the left. The right hemidiaphragm is depressed.

\section{REFERENCES}

1. McGee DC, Gould MK. Preventing complications of central venous catheterization. N Engl J Med 2003;348:1123-33.

2. Eisen LA, Narasimhan M, Berger JS, Mayo PH, Rosen MJ, Schneider RF. Mechanical complications of central venous catheters. J Intensive Care Med 2006;21:40-6.

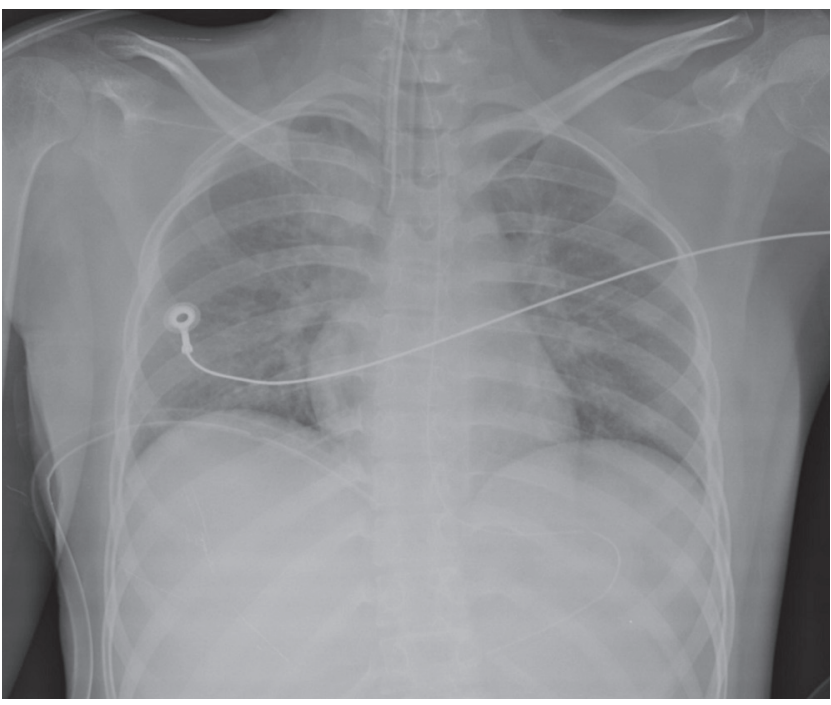

Figure 2. Chest X-ray showing chest tube positioning and improved tension pneumothorax.

3. Roberts DJ, Leigh-Smith S, Faris PD, Blackmore C, Ball CG, Robertson HL, et al. Clinical presentation of patients with tension pneumothorax: a systematic review. Ann Surg 2015;261: 1068-78.

4. Plewa MC, Ledrick D, Sferra JJ. Delayed tension pneumothorax complicating central venous catheterization and positive pressure ventilation. Am J Emerg Med 1995;13:532-5. 